\title{
Atomic structure of the carbon like ion Ca XV
}

\author{
N. Alwadie ${ }^{1,2}$, A. Almodlej ${ }^{1}$, N. Ben Nessib ${ }^{1,3}$ \\ and M.S. Dimitrijevicic ${ }^{4,5}$ \\ 1 Department of Physics and Astronomy, College of Sciences, King Saud \\ University, Saudi Arabia \\ 2 Department of Physics, College of Sciences, King Khalid University, Saudi \\ Arabia \\ 3 GRePAA, INSAT, Centre Urbain Nord, University of Carthage, Tunis, \\ Tunisia \\ 4 Astronomical Observatory, Volgina 7, 11060 Belgrade 38, Serbia \\ 5 Sorbonne Université, Observatoire de Paris, Université PSL, CNRS, \\ LERMA, F-92190 Meudon, France
}

Received: July 31, 2019; Accepted: September 28, 2019

\begin{abstract}
Energy levels, oscillator strengths and transition probabilities for the multicharged carbon like Ca XV ion have been calculated using the pseudorelativistic Hartree-Fock (HFR) approach using the new Cowan atomic structure code 2018. Results have been compared with NIST datdabase and other calculated data. There are great lack on atomic structure data of Ca XV and obtained new data will be important for plasma diagnostic and astrophysical modeling.
\end{abstract}

Key words: spectral lines - energy levels - oscillator strengths -transition probabilities

\section{Introduction}

Carbon-like ions are highly abundant elements and their lines are prominent in both stellar and interstellar spectra and they are interesting for possible astrophysical plasma diagnostic applications (Al-Modlej et al., 2018). One example of them is calcium $(\mathrm{Ca})$ which has a nuclear charge $\mathrm{Z}=20$ and it has cosmic abundances in astrophysical spectra (Träbert et al., 2018). Carbon-like ions are also important for investigation in plasma physics, fusion research and plasma technologies.

In general, we can obtain ionized calcium by Tokamaks which are proven light sources suitable for measuring spectra of astrophysical relevance (Träbert et al., 2018), as well as by the solar flare plasma where Extreme Ultra-Violet (EUV) solar emission lines of highly ionized calcium have been recorded (Nahar, 2017). 
Indeed, what is interesting now is the study of Ca XV, a highly charged carbon-like ion that typically exists in high temperature plasmas and plays an important role for diagnostics and modeling.

Researchers have done some important experimental studies on spectral lines of $\mathrm{Ca} \mathrm{XV}$ where the diagnostic potential of these lines was noted. It is worth mentioning that the data on atomic properties are not only relevant to spectroscopy, but these values are of interest in a variety of other fields in physics and technology (Colón and Alonso-Medina, 2010). As an example, the diagnostic emission lines have been frequently observed in solar EUV spectra of carbon-like Ca XV by Dere (1978). Moreover, Ca XV was detected in the Extreme-Ultraviolet Explorer satellite spectrum of the star $\xi$ Bootis A (Laming and Drake, 1999). Also, EUV emission lines of Ca XV in solar and laboratory spectra were studied by Keenan et al. (2003).

Recently, the most important experimental study in this field was by Trbert et al. (2018), where they investigated the emission line intensity pattern of highly charged $\mathrm{Ca}$ and Ar in the EUV in a laboratory plasma, by using a Tokamak plasma discharge in hydrogen carrying some Ar and intermittently seeded with Ca. The task is done injecting these elements by laser pulse into a plasma dominated by hydrogen. Fortunately, the results of the study of spectrum for Ca produced a fair number of spectral lines. The data of this experimental study have been compared with databases especially CHIANTI (Dere et al., 2019). Most importantly, they found that Ca XV is particularly rich in lines in the EUV spectral range and the strongest line was $2 \mathrm{~s}^{2} 2 \mathrm{p}^{2}{ }^{1} \mathrm{D}_{2}-2 \mathrm{~s} 2 \mathrm{p}^{3}{ }^{1} \mathrm{D}_{2}^{o}$ at $\lambda=161.1 \AA$.

In the present work, we calculated energy levels for the configuration expansion: $2 \mathrm{~s}^{2} 2 \mathrm{p}^{2}, 2 \mathrm{~s}^{2} 2 \mathrm{p} 3 \mathrm{p}, 2 \mathrm{~s}^{2} 2 \mathrm{p} 4 \mathrm{p}, 2 \mathrm{~s} 2 \mathrm{p}^{3}, 2 \mathrm{~s}^{2} 2 \mathrm{p} 3 \mathrm{~s}, 2 \mathrm{~s}^{2} 2 \mathrm{p} 4 \mathrm{~s}, 2 \mathrm{~s}^{2} 2 \mathrm{p} 5 \mathrm{~s}$ and $2 \mathrm{~s}^{2}$ $2 \mathrm{p} 3 \mathrm{~d}$. Also, we computed oscillator strengths and transition probabilities corresponding to some spectral lines of the carbon like Ca XV ion using a relativistic configuration interaction method based on numerical wave functions calculated with a single configurations Hartree-Fock Relativistic (HFR) approach including core-polarization potential and the corresponding corrections in the matrix elements because for any system considered, complex like Ca XV ion, both relativistic and correlation effects could be relevant. So, all our calculations were in the framework of the HFR by means of a recent version of the Cowan computer code adapted by Kramida (2018).

We describe in Section 2 the theoretical calculations and then in Section 3 the results of the atomic structure of $\mathrm{Ca} \mathrm{XV}$ ion. The conclusions are presented in Section 4.

\section{Hartree-Fock Relativistic method}

For the hydrogen atom, the Schrödinger equation is solved exactly, but for a system consisting of a multi-electron atom or molecule, we must use approx- 
imate methods such as the HFR method, where the Schrödinger equation for $N$-electrons atom wavefunction can be written as:

$$
\left[\sum_{i=1}^{N}\left(-\frac{1}{2} \nabla_{r_{i}}^{2}-\frac{Z}{r_{i}}\right)+\sum_{i<j}^{N} \frac{1}{r_{i j}}\right] \Psi\left(q_{1}, q_{2}, \ldots, q_{N}\right)=E \Psi\left(q_{1}, q_{2}, \ldots, q_{N}\right)
$$

where $q_{i}$ denotes the set of the discrete spin variable of electron $i$ and continuous spatial coordinates $r_{i}$.

In this method, the many wave functions are written as a linear superposition of products of single-particle spin orbitals wave functions but these wave functions, anti-symmetric for $N$-electrons, must satisfy the Pauli principle. So, this product is written as a determinant known as the Slater Determinant (Bransden \& Joachain, 2003):

$$
\Psi\left(q_{1}, q_{2}, \ldots, q_{N}\right)=\frac{1}{\sqrt{N !}}\left|\begin{array}{cccc}
u_{\alpha}\left(q_{1}\right) & u_{\beta}\left(q_{1}\right) & \cdots & u_{\nu}\left(q_{1}\right) \\
u_{\alpha}\left(q_{2}\right) & u_{\beta}\left(q_{2}\right) & \cdots & u_{\nu}\left(q_{2}\right) \\
\vdots & \ldots & \cdots & \vdots \\
u_{\alpha}\left(q_{N}\right) & u_{\beta}\left(q_{N}\right) & \cdots & u_{\nu}\left(q_{N}\right)
\end{array}\right|
$$

The functions $u_{\lambda}\left(q_{i}\right)$ satisfy the HartreeFock Relativistic equation (Al-Towyan et al., 2016; Colón and Alonso-Medina, 2010):

$$
\begin{gathered}
{\left[-\frac{1}{2} \nabla_{r_{i}}^{2}-\frac{Z}{r_{i}}\right] u_{\lambda}\left(q_{i}\right)+\left[\sum_{\mu} \int u_{\mu}^{*}\left(q_{i}\right) \frac{1}{r_{i j}} u_{\mu}\left(q_{j}\right) d q_{j}\right] u_{\lambda}\left(q_{i}\right)} \\
-\left[\sum_{\mu} \int u_{\mu}^{*}\left(q_{j}\right) \frac{1}{r_{i j}} u_{\lambda}\left(q_{j}\right) d q_{j}\right] u_{\lambda}\left(q_{i}\right)=E_{\lambda} u_{\lambda}\left(q_{i}\right)
\end{gathered}
$$

where $\lambda, \mu=\alpha, \beta, \ldots, \nu$ and the summation over $\mu$ extends over the $N$ occupied spin-orbitals.

We note from Eq. (2) that the determinant vanishes if two electrons are the same. That means the Hartree wavefunction is anti-symmetric with respect to the interchange of any set of space-spin coordinates of any two particles, but its Hamiltonian must be invariant under this condition. From here it was necessary to introduce the relativistic corrections with a Breit-Pauli Hamiltonian including mass-variation term, one-body Darwin term and Blume-Watson spin-orbit term which contain the part of the Breit interaction that can be reduced to a one-body operator, also treated by the perturbation theory Alonizan et al. (2016).

In previous works (Alonizan et al. (2016), for example), we obtained better results with HFR method comparing to similar methods as TFDA potential method; which gives advantage of this method.

The Cowan (CW) code, a suite of four atomic structure programs (RCN, RCN2, RCG and RCE) version 2018 (Kramida, 2018), uses this HFR method. The three first codes are for $a b$ initio atomic structure calculations and the 
fourth one (RCE) is used to have least-squares fit calculations using an iterative procedure (Cowan, 1981).

\section{Atomic structure of the ion Ca XV}

We performed calculations of energy levels for the carbon-like ion Ca XV by the suite of atomic structure codes of Cowan adapted by Kramida (2018). The configuration expansion of the basis set used in this work consists of 3 even parity configurations: $2 \mathrm{~s}^{2} 2 \mathrm{p}^{2}$ and $2 \mathrm{~s}^{2} 2 \mathrm{p} n \mathrm{p}(n=3,4)$ and 5 odd parity configurations: $2 \mathrm{~s} 2 \mathrm{p}^{3}, 2 \mathrm{~s}^{2} 2 \mathrm{p} n \mathrm{~s}(n=3,4,5)$ and $2 \mathrm{~s}^{2} 2 \mathrm{p} 3 \mathrm{~d}$.

The calculated values of energy levels and oscillator strengths obtained with this code have been compared with other theoretical methods (Ekman et al., 2014), and with data from NIST database (Kramida et al., 2018).

\subsection{Energy levels of the ion Ca XV}

In Tables 1 to 5 , we list energy levels of the configurations $2 \mathrm{~s}^{2} 2 \mathrm{p}^{2}, 2 \mathrm{~s} 2 \mathrm{p}^{3}$, $2 \mathrm{~s}^{2} 2 \mathrm{p} n \mathrm{~s}(n=3,4,5), 2 \mathrm{~s}^{2} 2 \mathrm{p} n \mathrm{p}(n=3,4), 2 \mathrm{~s}^{2} 2 \mathrm{p} 3 \mathrm{~d}$ for Ca XV ion. The obtained values are compared with those of NIST atomic database (Kramida et al., 2018) and with Ekman et al. (2014) values which are calculated using the Multi-Configuration Hartree-Fock (MCHF) method.

Table 1. "Energy levels for the configuration $2 \mathrm{~s}^{2} 2 \mathrm{p}^{2}$ of Ca XV." E(NIST) are from NIST database, $\mathrm{E}(\mathrm{CW})$ are the energy levels calculated by using the Cowan $(\mathrm{CW})$ code, and $\mathrm{E}(\mathrm{EK})$ calculated using $(\mathrm{MCDHF})$ by Ekman et al. All energies are in $\mathrm{cm}^{-1}$.

\begin{tabular}{lccrrr}
\hline \hline Conf. & Term & $\mathrm{J}$ & $\mathrm{E}(\mathrm{NIST})$ & $\mathrm{E}(\mathrm{CW})$ & $\mathrm{E}(\mathrm{EK})$ \\
\hline $2 \mathrm{~s}^{2} 2 \mathrm{p}^{2}$ & ${ }^{3} \mathrm{P}$ & 0 & & & \\
$2 \mathrm{~s}^{2} 2 \mathrm{p}^{2}$ & ${ }^{3} \mathrm{P}$ & 1 & 17559 & 16353 & 17553 \\
$2 \mathrm{~s}^{2} 2 \mathrm{p}^{2}$ & ${ }^{3} \mathrm{P}$ & 2 & 35923 & 35171 & 35920 \\
$2 \mathrm{~s}^{2} 2 \mathrm{p}^{2}$ & ${ }^{1} \mathrm{D}$ & 2 & 108600 & 104491 & 108736 \\
$2 \mathrm{~s}^{2} 2 \mathrm{p}^{2}$ & ${ }^{1} \mathrm{~S}$ & 0 & 197670 & 214620 & 197839 \\
\hline \hline
\end{tabular}

For the configuration $2 \mathrm{~s}^{2} 2 \mathrm{p}^{2}$, CW code gives close to results to NIST. The results differ by about $4 \%$ from the NIST values, while, Ekman et al. values are very close to the NIST database values by $0.1 \%$.

For the configuration $2 \mathrm{~s} 2 \mathrm{p}^{3}$, the CW code gives values $5.6 \%$ higher than NIST database. Ekman et al. values are roughly the same differing by only $0.02 \%$ from the NIST ones. 
Table 2. Same as Table 1, but for configuration $2 \mathrm{~s} 2 \mathrm{p}^{3}$ of Ca XV.

\begin{tabular}{lccccc}
\hline \hline Conf. & Term & $\mathrm{J}$ & $\mathrm{E}(\mathrm{NIST})$ & $\mathrm{E}(\mathrm{CW})$ & $\mathrm{E}(\mathrm{EK})$ \\
\hline $2 \mathrm{~s} 2 \mathrm{p}^{3}$ & ${ }^{5} \mathrm{~S}^{o}$ & 2 & 275900 & 311928 & 275788 \\
$2 \mathrm{~s} 2 \mathrm{p}^{3}$ & ${ }^{3} \mathrm{D}^{o}$ & 3 & 500230 & 533862 & 500273 \\
$2 \mathrm{~s} 2 \mathrm{p}^{3}$ & ${ }^{3} \mathrm{D}^{o}$ & 2 & 496680 & 529034 & 496724 \\
$2 \mathrm{~s} 2 \mathrm{p}^{3}$ & ${ }^{3} \mathrm{D}^{o}$ & 1 & 497570 & 529652 & 497632 \\
$2 \mathrm{~s} 2 \mathrm{p}^{3}$ & ${ }^{3} \mathrm{P}^{o}$ & 1 & 582780 & 607890 & 582942 \\
$2 \mathrm{~s} 2 \mathrm{p}^{3}$ & ${ }^{3} \mathrm{P}^{o}$ & 2 & 585670 & 611053 & 585800 \\
$2 \mathrm{~s} 2 \mathrm{p}^{3}$ & ${ }^{3} \mathrm{P}^{o}$ & 0 & 581730 & 606177 & 581886 \\
$2 \mathrm{~s} 2 \mathrm{p}^{3}$ & ${ }^{1} \mathrm{D}^{o}$ & 2 & 729650 & 759011 & 730043 \\
$2 \mathrm{~s} 2 \mathrm{p}^{3}$ & ${ }^{3} \mathrm{~S}^{o}$ & 1 & 728880 & 757132 & 729176 \\
$2 \mathrm{~s} 2 \mathrm{p}^{3}$ & ${ }^{1} \mathrm{P}^{o}$ & 1 & 814380 & 835599 & 814815 \\
\hline \hline
\end{tabular}

Table 3. Same as Table 1 , but for configurations $2 \mathrm{~s}^{2} 2 \mathrm{p} n \mathrm{~s}(n=3,4,5)$ of Ca XV.

\begin{tabular}{cccccc}
\hline \hline Conf. & Term & $\mathrm{J}$ & $\mathrm{E}(\mathrm{NIST})$ & $\mathrm{E}(\mathrm{CW})$ & $\mathrm{E}(\mathrm{EK})$ \\
\hline $2 \mathrm{~s}^{2} 2 \mathrm{p} 3 \mathrm{~s}$ & ${ }^{3} \mathrm{P}^{o}$ & 0 & - & 4392032 & 4079795 \\
$2 \mathrm{~s}^{2} 2 \mathrm{p} 3 \mathrm{~s}$ & ${ }^{3} \mathrm{P}^{o}$ & 1 & - & 4396297 & 4084845 \\
$2 \mathrm{~s}^{2} 2 \mathrm{p} 3 \mathrm{~s}$ & ${ }^{3} \mathrm{P}^{o}$ & 2 & - & 4428144 & 4115926 \\
$2 \mathrm{~s}^{2} 2 \mathrm{p} 3 \mathrm{~s}$ & ${ }^{1} \mathrm{P}^{o}$ & 1 & - & 4441352 & 4134012 \\
$2 \mathrm{~s}^{2} 2 \mathrm{p} 4 \mathrm{~s}$ & ${ }^{3} \mathrm{P}^{o}$ & 0 & - & 4395728 & 5520070 \\
$2 \mathrm{~s}^{2} 2 \mathrm{p} 4 \mathrm{~s}$ & ${ }^{3} \mathrm{P}^{o}$ & 1 & - & 4396731 & 5522133 \\
$2 \mathrm{~s}^{2} 2 \mathrm{p} 4 \mathrm{~s}$ & ${ }^{3} \mathrm{P}^{o}$ & 2 & - & 4431652 & 5556429 \\
$2 \mathrm{~s}^{2} 2 \mathrm{p} 4 \mathrm{~s}$ & ${ }^{1} \mathrm{P}^{o}$ & 1 & - & 4433840 & 5561725 \\
$2 \mathrm{~s}^{2} 2 \mathrm{p} 5 \mathrm{~s}$ & ${ }^{3} \mathrm{P}^{o}$ & 0 & - & 4657441 & - \\
$2 \mathrm{~s}^{2} 2 \mathrm{p} 5 \mathrm{~s}$ & ${ }^{3} \mathrm{P}^{o}$ & 1 & - & 4657861 & - \\
$2 \mathrm{~s}^{2} 2 \mathrm{p} 5 \mathrm{~s}$ & ${ }^{3} \mathrm{P}^{o}$ & 2 & - & 4693386 & - \\
$2 \mathrm{~s}^{2} 2 \mathrm{p} 5 \mathrm{~s}$ & ${ }^{1} \mathrm{P}^{o}$ & 1 & - & 4694256 & - \\
\hline \hline
\end{tabular}

For the configurations $2 \mathrm{~s}^{2} 2 \mathrm{p} n \mathrm{~s}(n=3,4,5)$ and $2 \mathrm{~s}^{2} 2 \mathrm{p} n \mathrm{p}(n=3,4)$ the NIST values do not exist for comparison. It should be noted that, we have obtained new energy values that do not exist in Ekman et al. for the configuration $2 \mathrm{~s}^{2} 2 \mathrm{p} 5 \mathrm{~s}$ and for the term $2 \mathrm{~s}^{2} 2 \mathrm{p} 4 \mathrm{p}{ }^{1} \mathrm{~S}$. 
Table 4. Same as Table 1, but for configurations $2 \mathrm{~s}^{2} 2 \mathrm{p} n \mathrm{p}(n=3,4)$ of Ca XV.

\begin{tabular}{|c|c|c|c|c|c|}
\hline 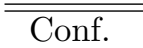 & Term & 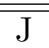 & 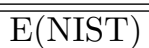 & $\overline{\mathrm{E}(\mathrm{CW})}$ & $\overline{\mathrm{E}(\mathrm{EK})}$ \\
\hline $2 \mathrm{~s}^{2} 2 \mathrm{p} 3 \mathrm{p}$ & ${ }^{3} \mathrm{~S}$ & 1 & - & 4476007 & 4257457 \\
\hline $2 \mathrm{~s}^{2} 2 \mathrm{p} 3 \mathrm{p}$ & ${ }^{1} \mathrm{P}$ & 1 & - & 4446957 & 4228086 \\
\hline $2 \mathrm{~s}^{2} 2 \mathrm{p} 3 \mathrm{p}$ & ${ }^{3} \mathrm{D}$ & 1 & - & 4424400 & 4205709 \\
\hline $2 \mathrm{~s}^{2} 2 \mathrm{p} 3 \mathrm{p}$ & ${ }^{3} \mathrm{D}$ & 2 & - & 4445944 & 4229376 \\
\hline $2 \mathrm{~s}^{2} 2 \mathrm{p} 3 \mathrm{p}$ & ${ }^{3} \mathrm{D}$ & 3 & - & 4472023 & 4255295 \\
\hline $2 \mathrm{~s}^{2} 2 \mathrm{p} 3 \mathrm{p}$ & ${ }^{3} \mathrm{P}$ & 0 & - & 4475994 & 4250224 \\
\hline $2 \mathrm{~s}^{2} 2 \mathrm{p} 3 \mathrm{p}$ & ${ }^{3} \mathrm{P}$ & 1 & - & 4494910 & 4270847 \\
\hline $2 \mathrm{~s}^{2} 2 \mathrm{p} 3 \mathrm{p}$ & ${ }^{3} \mathrm{P}$ & 2 & - & 4501838 & 4276163 \\
\hline $2 \mathrm{~s}^{2} 2 \mathrm{p} 3 \mathrm{p}$ & ${ }^{1} \mathrm{D}$ & 2 & - & 4528268 & 4314496 \\
\hline $2 \mathrm{~s}^{2} 2 \mathrm{p} 3 \mathrm{p}$ & ${ }^{1} \mathrm{~S}$ & 0 & - & 4567681 & 4361378 \\
\hline $2 \mathrm{~s}^{2} 2 \mathrm{p} 4 \mathrm{p}$ & ${ }^{3} \mathrm{~S}$ & 1 & - & 4491238 & 5618735 \\
\hline $2 \mathrm{~s}^{2} 2 \mathrm{p} 4 \mathrm{p}$ & ${ }^{1} \mathrm{P}$ & 1 & - & 4487896 & 5612050 \\
\hline $2 \mathrm{~s}^{2} 2 \mathrm{p} 4 \mathrm{p}$ & ${ }^{3} \mathrm{D}$ & 1 & - & 4450829 & 5572096 \\
\hline $2 \mathrm{~s}^{2} 2 \mathrm{p} 4 \mathrm{p}$ & ${ }^{3} \mathrm{D}$ & 2 & - & 4456178 & 5583680 \\
\hline $2 \mathrm{~s}^{2} 2 \mathrm{p} 4 \mathrm{p}$ & ${ }^{3} \mathrm{D}$ & 3 & - & 4488453 & 5613455 \\
\hline $2 \mathrm{~s}^{2} 2 \mathrm{p} 4 \mathrm{p}$ & ${ }^{3} \mathrm{P}$ & 0 & - & 4459660 & 5590557 \\
\hline $2 \mathrm{~s}^{2} 2 \mathrm{p} 4 \mathrm{p}$ & ${ }^{3} \mathrm{P}$ & 1 & - & 4455693 & 5582839 \\
\hline $2 \mathrm{~s}^{2} 2 \mathrm{p} 4 \mathrm{p}$ & ${ }^{3} \mathrm{P}$ & 2 & - & 4491171 & 5619232 \\
\hline $2 \mathrm{~s}^{2} 2 \mathrm{p} 4 \mathrm{p}$ & ${ }^{1} \mathrm{D}$ & 2 & - & 4496043 & 5631037 \\
\hline $2 \mathrm{~s}^{2} 2 \mathrm{p} 4 \mathrm{p}$ & ${ }^{1} \mathrm{~S}$ & 0 & - & 4501924 & - \\
\hline
\end{tabular}

Table 5. Same as Table 1, but for configuration $2 \mathrm{~s}^{2} 2 \mathrm{p} 3 \mathrm{~d}$ of Ca XV.

\begin{tabular}{cccccc}
\hline \hline Conf. & Term & $\mathrm{J}$ & $\mathrm{E}(\mathrm{NIST})$ & $\mathrm{E}(\mathrm{CW})$ & $\mathrm{E}(\mathrm{EK})$ \\
\hline $2 \mathrm{~s}^{2}$ 2p3d & ${ }^{3} \mathrm{~F}^{o}$ & 2 & 4363300 & 3951477 & 4363635 \\
$2 \mathrm{~s}^{2}$ 2p3d & ${ }^{3} \mathrm{~F}^{o}$ & 3 & 4379400 & 3963833 & 4378814 \\
$2 \mathrm{~s}^{2} 2 \mathrm{p} 3 \mathrm{~d}$ & ${ }^{3} \mathrm{~F}^{o}$ & 4 & - & 3988654 & 4401309 \\
$2 \mathrm{~s}^{2} 2 \mathrm{p} 3 \mathrm{~d}$ & ${ }^{1} \mathrm{D}^{o}$ & 2 & - & 3966033 & 4385007 \\
$2 \mathrm{~s}^{2} 2 \mathrm{p} 3 \mathrm{~d}$ & ${ }^{3} \mathrm{D}^{o}$ & 1 & 4399500 & 3975409 & 4402470 \\
$2 \mathrm{~s}^{2} 2 \mathrm{p} 3 \mathrm{~d}$ & ${ }^{3} \mathrm{D}^{o}$ & 2 & 4411500 & 3991878 & 4413002 \\
$2 \mathrm{~s}^{2} 2 \mathrm{p} 3 \mathrm{~d}$ & ${ }^{3} \mathrm{D}^{o}$ & 3 & 4426400 & 4000316 & 4425526 \\
$2 \mathrm{~s}^{2} 2 \mathrm{p} 3 \mathrm{~d}$ & ${ }^{3} \mathrm{P}^{o}$ & 2 & 4435400 & 4006954 & 4433389 \\
$2 \mathrm{~s}^{2} 2 \mathrm{p} 3 \mathrm{~d}$ & ${ }^{3} \mathrm{P}^{o}$ & 1 & 4434500 & 4008947 & 4435381 \\
$2 \mathrm{~s}^{2} 2 \mathrm{p} 3 \mathrm{~d}$ & ${ }^{3} \mathrm{P}^{o}$ & 0 & - & 4010358 & 4436968 \\
$2 \mathrm{~s}^{2} 2 \mathrm{p} 3 \mathrm{~d}$ & ${ }^{1} \mathrm{~F}^{o}$ & 3 & 4475000 & 4032514 & 4474373 \\
$2 \mathrm{~s}^{2} 2 \mathrm{p} 3 \mathrm{~d}$ & ${ }^{1} \mathrm{P}^{o}$ & 1 & 4473400 & 4032524 & 4475119 \\
\hline \hline
\end{tabular}


Moreover, with respect to the configuration $2 \mathrm{~s}^{2} 2 \mathrm{p} 3 \mathrm{~d}$, some values of ${ }^{3} \mathrm{~F}_{4}^{o}$, ${ }^{1} \mathrm{D}^{o}$ and ${ }^{3} \mathrm{P}_{0}^{o}$ terms in NIST database do not exist and for the existing data, the CW code gives results $9.6 \%$ higher than the NIST values but Ekman et al. values stays very close at the same rate from NIST. Indeed, we recommend the use of our CW results, because of the fact that we got new values with the CW code that are not present in the NIST database.

\subsection{Oscillator strengths of the ion Ca XV}

Instead of the absorption oscillator strengths $f_{i j}$ or the emission oscillator strengths $f_{j i}$, we use the weighted oscillator strengths $g f$ :

$$
g f=g_{i} f_{i j}=g_{f} f_{j i}
$$

The weighted oscillator strengths and transition probabilities for selected allowed transitions $2 \mathrm{~s}^{2} 2 \mathrm{p}^{2}{ }^{3} \mathrm{P}-2 \mathrm{~s} 2 \mathrm{p}^{3}{ }^{3} \mathrm{~S}^{o}, 2 \mathrm{~s}^{2} 2 \mathrm{p}^{2}{ }^{3} \mathrm{P}-2 \mathrm{~s} 2 \mathrm{p}^{3}{ }^{3} \mathrm{P}^{o}$ and $2 \mathrm{~s}^{2} 2 \mathrm{p}^{2}$ ${ }^{3} \mathrm{P}-2 \mathrm{~s} 2 \mathrm{p}^{3}{ }^{3} \mathrm{D}^{o}$ were computed using the $\mathrm{CW}$ code adapted by Kramida (2018).

Tables from 6 to 8 give the weighted oscillator strengths and transition probability values of these transitions for $\mathrm{Ca} \mathrm{XV}$ ion obtained $a b$ initio by $\mathrm{CW}$ code and just compared with Ekman et al. (2014) values which are calculated using the MCHF method because there is no data to compare in NIST atomic database (Kramida et al., 2018).

Table 6. Weighted oscillator strengths and transition probabilities for the transition $\left(2 \mathrm{~s}^{2} 2 \mathrm{p}^{2}{ }^{3} \mathrm{P}-2 \mathrm{~s} 2 \mathrm{p}^{3}{ }^{3} \mathrm{~S}^{o}\right)$ of $\mathrm{Ca} \mathrm{XV}$ ion. $\log g f(\mathrm{CW}), \log g f(\mathrm{EK})$ and $g A(\mathrm{CW})$ and $g A(\mathrm{EK})$ are the weighted oscillator strengths and transition probabilities calculated by us and by Ekman et al. using the Cowan and (MCDHF) respectively. $g_{i}$ and $g_{k}$ are respectively the statistical wights of the term ${ }^{3} \mathrm{P}-{ }^{3} \mathrm{~S}^{o}$.

\begin{tabular}{ccccccc}
\hline & & & \multicolumn{2}{c}{$\log g f$} & \multicolumn{2}{c}{$g A$} \\
\cline { 5 - 7 }$\lambda(\mathrm{nm})$ & $g_{i}$ & $g_{k}$ & $(\mathrm{CW})$ & $(\mathrm{EK})$ & $(\mathrm{CW})$ & $(\mathrm{EK})$ \\
\hline 13.9 & 5 & 3 & -0.317 & -0.462 & $1.68 \mathrm{E}+11$ & $1.11 \mathrm{E}+11$ \\
13.5 & 3 & 3 & -0.599 & -0.762 & $9.22 \mathrm{E}+10$ & $5.82 \mathrm{E}+10$ \\
13.2 & 1 & 3 & -1.076 & -1.249 & $3.21 \mathrm{E}+10$ & $2.00 \mathrm{E}+10$ \\
\hline
\end{tabular}

So, for the results of weighted oscillator strengths $\log g f$ for selected transitions, we found that our results for $2 \mathrm{~s}^{2} 2 \mathrm{p}^{2}{ }^{3} \mathrm{P}-2 \mathrm{~s} 2 \mathrm{p}^{3}{ }^{3} \mathrm{P}^{o}$ transitions were in a good agreement (the difference is $3.6 \%$ for $\log g f$ ) with the values of Ekman et al. Also, for the other transitions, the results differ from the Ekman et al. values by about $20 \%$ for $2 \mathrm{~s}^{2} 2 \mathrm{p}^{2}{ }^{3} \mathrm{P}-2 \mathrm{~s} 2 \mathrm{p}^{3}{ }^{3} \mathrm{~S}^{o}$ and $17 \%$ for $2 \mathrm{~s}^{2} 2 \mathrm{p}^{2}{ }^{3} \mathrm{P}-2 \mathrm{~s} 2 \mathrm{p}^{3}$ ${ }^{3} \mathrm{D}^{o}$.

On the other hand, the results for transition probabilities $g A$ for selected transitions were compared to the values of the Ekman et al.: The CW calculated 
Table 7. Same as Table 6 , but for the transition $\left(2 \mathrm{~s}^{2} 2 \mathrm{p}^{2}{ }^{3} \mathrm{P}-2 \mathrm{~s} 2 \mathrm{p}^{3}{ }^{3} \mathrm{P}^{o}\right)$ of Ca XV.

\begin{tabular}{ccccccc}
\hline & & & \multicolumn{2}{c}{$\log g f$} & \multicolumn{2}{c}{$g A$} \\
\cline { 5 - 8 }$\lambda(\mathrm{nm})$ & $g_{i}$ & $g_{k}$ & $(\mathrm{CW})$ & $(\mathrm{EK})$ & $(\mathrm{CW})$ & $(\mathrm{EK})$ \\
\hline 17.46058 & 5 & 3 & -1.34 & -1.32 & $1.01 \mathrm{E}+10$ & $9.54 \mathrm{E}+09$ \\
17.36467 & 5 & 5 & -0.59 & -0.61 & $5.75 \mathrm{E}+10$ & $4.91 \mathrm{E}+10$ \\
16.95419 & 3 & 1 & -1.25 & -1.25 & $1.31 \mathrm{E}+10$ & $1.20 \mathrm{E}+10$ \\
16.90512 & 3 & 3 & -1.07 & -1.12 & $1.98 \mathrm{E}+10$ & $1.61 \mathrm{E}+10$ \\
16.8152 & 3 & 5 & -1.68 & -1.54 & $4.94 \mathrm{E}+09$ & $6.15 \mathrm{E}+09$ \\
16.45036 & 1 & 3 & -1.41 & -1.37 & $9.59 \mathrm{E}+09$ & $9.66 \mathrm{E}+09$ \\
\hline
\end{tabular}

Table 8. Same as Table 6 , but for the transition $\left(2 \mathrm{~s}^{2} 2 \mathrm{p}^{2}{ }^{3} \mathrm{P}-2 \mathrm{~s} 2 \mathrm{p}^{3}{ }^{3} \mathrm{D}^{o}\right)$ of Ca XV.

\begin{tabular}{lcccccc}
\hline & & & \multicolumn{2}{c}{$\log g f$} & \multicolumn{2}{c}{$g A$} \\
\cline { 4 - 7 }$\lambda(\mathrm{nm})$ & $g_{i}$ & $g_{k}$ & $(\mathrm{CW})$ & $(\mathrm{EK})$ & $(\mathrm{CW})$ & $(\mathrm{EK})$ \\
\hline 20.25 & 5 & 5 & -1.790 & -2.105 & $2.64 \mathrm{E}+09$ & $1.11 \mathrm{E}+09$ \\
20.22 & 5 & 3 & -2.992 & -3.365 & $1.66 \mathrm{E}+08$ & $6.15 \mathrm{E}+07$ \\
20.05 & 5 & 7 & -0.500 & -0.699 & $5.24 \mathrm{E}+10$ & $2.88 \mathrm{E}+10$ \\
19.51 & 3 & 5 & -0.644 & -0.815 & $3.98 \mathrm{E}+10$ & $2.34 \mathrm{E}+10$ \\
19.48 & 3 & 3 & -1.399 & -1.616 & $7.02 \mathrm{E}+09$ & $3.72 \mathrm{E}+09$ \\
18.88 & 1 & 3 & -0.956 & -1.126 & $2.07 \mathrm{E}+10$ & $1.24 \mathrm{E}+10$ \\
\hline
\end{tabular}

data for $2 \mathrm{~s}^{2} 2 \mathrm{p}^{2}{ }^{3} \mathrm{P}-2 \mathrm{~s} 2 \mathrm{p}^{3}{ }^{3} \mathrm{P}^{o}$ transition was in average less than $13 \%$ higher of the Ekman et al. values, but for $2 \mathrm{~s}^{2} 2 \mathrm{p}^{2}{ }^{3} \mathrm{P}-2 \mathrm{~s} 2 \mathrm{p}^{3}{ }^{3} \mathrm{~S}^{o}$ transition was in average $57 \%$ higher of the Ekman et al. values and for $2 \mathrm{~s}^{2} 2 \mathrm{p}^{2}{ }^{3} \mathrm{P}-2 \mathrm{~s} 2 \mathrm{p}^{3}{ }^{3} \mathrm{D}^{o}$ transition the difference reach $100 \%$.

\section{Conclusion}

When comparing the calculated energy levels with experimental values from NIST and the results from Ekman et al., we find that our results for configurations $2 \mathrm{~s}^{2} 2 \mathrm{p} 2,2 \mathrm{~s} 2 \mathrm{p}^{3}$ and $2 \mathrm{~s}^{2} 2 \mathrm{p} 3 \mathrm{~d}$ were close to the NIST database by about $4 \%$ to $9 \%$. While, for the other configurations, there are no values to compare with them in NIST, but we found values in the Ekman et al. for these configurations except the $2 \mathrm{~s}^{2} 2 \mathrm{p} 5 \mathrm{~s}$ configuration. So, we got new values with the CW code for the $\left(2 \mathrm{~s}^{2} 2 \mathrm{p} 5 \mathrm{~s}\right)$ configuration and for the term $\left(2 \mathrm{~s}^{2} 2 \mathrm{p} 4 \mathrm{p}{ }^{1} \mathrm{~S}\right)$ that did not exist before in any experimental data.

As for the results obtained with CW code for all the above transitions of weighted oscillator strengths $\log g f$ are in a good agreement with the values of Ekman et al. Also, the results of transition probabilities $g A$ for selected transitions are close to Ekman et al. values. For example, the weighted oscillator 
strengths and transition probabilities for $2 \mathrm{~s}^{2} 2 \mathrm{p}^{2}{ }^{3} \mathrm{P}-2 \mathrm{~s} 2 \mathrm{p}^{3}{ }^{3} \mathrm{P}^{o}$ transitions are in average $3.6 \%$ for $\log g f$ and $12 \%$ for $g A$ different from the values of Ekman et al.

As we mentioned before, there is no abundant data for Ca XV transitions in NIST database, where there are only 14 lines for it (Kramida et al., 2018). So, this study is extremely important to overcome this great lack on atomic structure data for $\mathrm{Ca} \mathrm{XV}$ ion and it provides the missing values of NIST database and supports the results given by Ekman et al. for the weighted oscillator strengths $g f$ and transition probabilities $g A$ which will be very important for the atomic data needed in astrophysical spectroscopy and laboratories.

Acknowledgements. This project was funded by the National Plan for Science, Technology and Innovation (MAARIFAH), King Abdulaziz City for Science and Technology, Kingdom of Saudi Arabia, Award Number (12-MAT2879-02).

\section{References}

Al-Modlej, A., Alraddadi, R.A.B., and Ben Nessib, N.: Energy levels and oscillator strengths for carbon isoelectronic sequence from C I to Ne V 2018, Eur. Phys. J. Plus 133, 379. DOI: 10.1140/epjp/i2018-12192-9

Alonizan, N., Qindeel, R., \& Ben Nessib, N., Atomic structure calculations for neutral oxygen. 2016, International Journal of Spectroscopy, 2016 DOI: $10.1155 / 2016 / 1697561$

Al-Towyan, A., Nessib, N.B., Alonizan, N., Qindeel, R., and Yacoub, N.: Stark widths dependence on electron temperature for neutral chromium spectral lines 2016, Eur. Phys. J. Plus 131, 9. DOI: 10.1140/epjp/i2016-16009-7

Bransden, B. \& Joachain, C. 2003, Physics of Atoms and Molecules, Prentice Hall

Colón, C., and Alonso-Medina, A.: Calculation of oscillator strengths, transition probabilities and radiative lifetimes of levels in Sn III 2010, J. Phys. B: At. Mol. Phys. 43, 165001. DOI: 10.1088/0953-4075/43/16/165001

Cowan, R.D.: The theory of atomic structure and spectra 1981, Los Alamos Series in Basic and Applied Sciences.

Dere, K.P.: Spectral lines observed in solar flares between 171 and 630 Angstroms. 1978, Astron. J. 221, 1062. DOI: $10.1086 / 156110$

Dere, K.P., Del Zanna, G., Young, P.R., Landi, E., and Sutherland, R.S.: CHIANTI-An Atomic Database for Emission Lines. XV. Version 9, Improvements for the X-Ray Satellite Lines 2019, The Astrophysical Journal Supplement Series 241, 22. DOI: $10.3847 / 1538-4365 / \mathrm{ab} 05 \mathrm{cf}$

Ekman, J., Jönsson, P., Gustafsson, S., Hartman, H., Gaigalas, G., Godefroid, M.R., and Froese Fischer, C.: Calculations with spectroscopic accuracy: energies, transition rates, and Landé $\mathrm{g}_{J}$-factors in the carbon isoelectronic sequence from Ar XIII to Zn XXV 2014, Astron. Astrophys. 564, A24. DOI: 10.1051/0004-6361/201323163 
Keenan, F.P., Aggarwal, K.M., Katsiyannis, A.C., and Reid, R.H.G.: Extreme Ultraviolet Emission Lines of Ca xv in Solar and Laboratory Spectra 2003, Solar Physics 217, 225. DOI: 10.1023/B:SOLA.0000006871.49518.eb

Kramida, A., A Suite of Atomic Structure Codes Originally Developed by RD Cowan Adapted for Windows-Based Personal Computers. Available: https://catalog.data.gov/dataset/a-suite-of-atomic-structure-codes-originally-

developed-by-r-d-cowan-adapted-for-windows-ba [2019, January 10]. DOI: $10.18434 / \mathrm{T} 4 / 1502500$

Kramida, A., Yu. Ralchenko, Reader, J., \& and NIST ASD Team. 2018, NIST Atomic Spectra Database (ver. 5.6.1), [Online]. Available: https://physics.nist.gov/asd [2019, April 18]. National Institute of Standards and Technology, Gaithersburg, MD.

Laming, J.M., and Drake, J.J.: Stellar Coronal Abundances. VI. The First Ionization Potential Effect and $\xi$ Bootis A: Solar-like Anomalies at Intermediate-Activity Levels 1999, Astron. J. 516, 324. DOI: 10.1086/307112

Nahar, S.N.: Photoionization of Ca XV with high energy features 2017, New Astronomy 51, 69. DOI: 10.1016/j.newast.2016.08.010

Träbert, E., Beiersdorfer, P., Lepson, J.K., Reinke, M.L., and Rice, J.E.: EUV Spectra and Line Ratios of Multiply Ionized Calcium and Argon Atoms in a Laboratory Plasma 2018, Astron. J. 865, 148. DOI: 10.3847/1538-4357/aadba7 